\title{
Early Detection and Diagnosis of Breast Cancer
}

\author{
Ingrid Schreer* \\ Mammazentrum Universitätsklinik Schleswig-Holstein, Campus Kiel, Germany
}

\section{Key Words}

Breast Cancer: detection, diagnosis, screening, ultrasound, MRI, percutaneous interventions

\section{Summary}

The the use of clinical examination as well as imagingguided percutaneous interventional procedures are reported. Indications differ depending on the focus: screening and early detection or on lesion assessment and the diagnostic process in case of symptoms. Determination of the levels of evidence and the recommendations were based on a literature review and a voting process within the AGO Breast Comission.
Early detection makes it possible to treat breast cancer at early stages and thus reduce mortality and morbidity of the disease. Randomized controlled trials proved the efficacy of mammography screening. In these trials screening was performed every 12-33 months. The WHO's International Agency for Research on Cancer recently published the results of a Working Group on the Evaluation of Cancer-Preventive Strategies which met in Lyon, France in March 2002 [1]. The general statement was that 'There is sufficient evidence for the efficacy of screening women aged 50-69 years by mammogra-

\footnotetext{
*As member of the Breast Commission, part of the AGO (Working Group Gynecologic Oncology, German Society of Obstetrics and Gynecology)
}

\section{Schlüsselwörter \\ Brustkrebs: Früherkennung, Diagnostik, Screening, Ultraschall, MRT, perkutane Interventionen}

\section{Zusammenfassung}

Es wird über den Einsatz von klinischer Untersuchung, Bildgebung und der bildgebend gesteuerten perkutanen Biopsie im Rahmen von Brustkrebsfrüherkennung und Abklärung berichtet. Die Indikationen unterscheiden sich zwangsläufig je nach Einsatz bei Früherkennung oder Abklärung mammographischer Auffälligkeiten bzw. der Diagnostik bei der symptomatischen Patientin. Die Bewertung der einzelnen Methoden und ihre Empfehlung erfolgte auf der Basis der aktuellen Literatur im Rahmen eines Abstimmungsprozesses innerhalb der Organkommission "Mamma» der AGO.

phy as the sole screening modality in reducing mortality from breast cancer. There is limited evidence for the efficacy of screening women aged 40-49 years by mammography as the sole screening modality in reducing mortality from breast cancer.' This resulted in the AGO recommendation not to screen women under the age of 40 and not to recommend explicitly screening for women between 40 and 49 years of age within a screening program. The same is true for women 70 years and older. Nevertheless, in both age groups mammography may be carried out in individual cases (fig. 1).

Breast ultrasound as a sole screening method is not recommended because evidence of efficacy is still missing. Results of ongoing randomized controlled trials are pending so that the value in terms of reducing mortality is unknown. As an adjunct to screening mammography in women with radiographically dense breasts it may increase sensitivity, but a concomi-

\begin{tabular}{ll}
\hline KARGER & ( ) 2006 S. Karger GmbH, Freiburg \\
Fax +497614520714 & Accessible online at: \\
$\begin{array}{l}\text { E-mail Information@Karger.de } \\
\text { www.karger.com }\end{array}$ & www.karger.com/brc
\end{tabular}




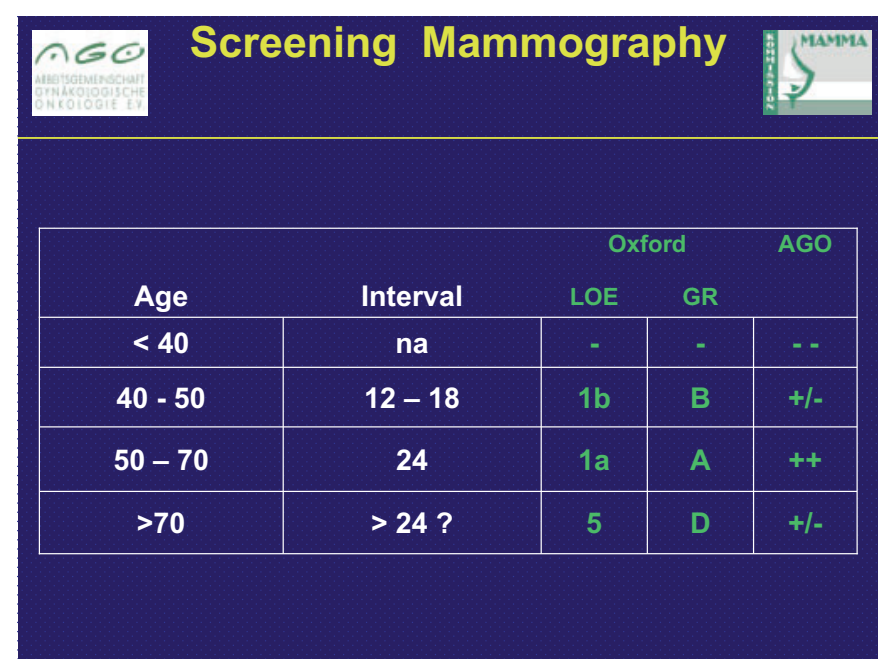

Fig. 1. Recommendations for screening mammography for different age groups.

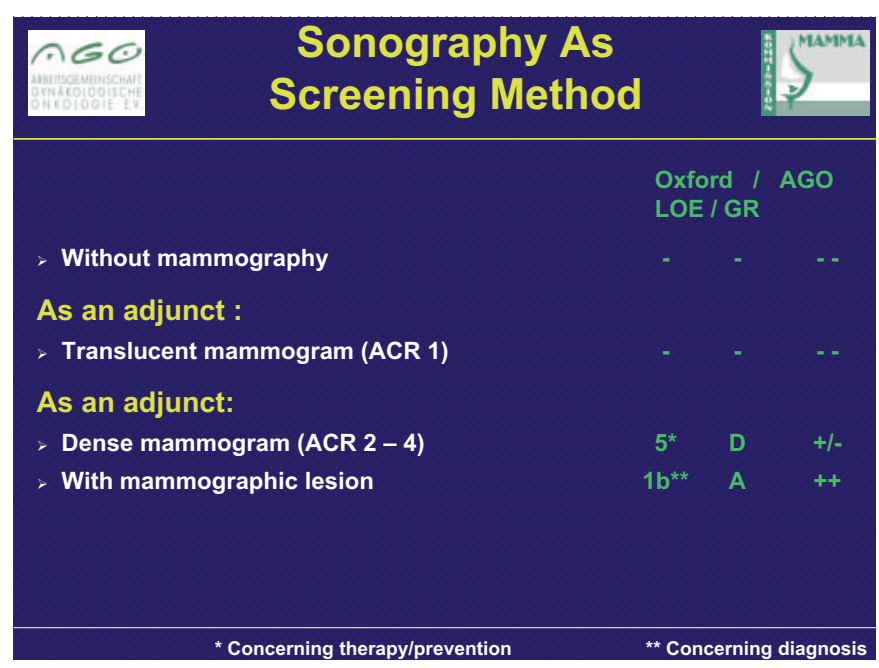

Fig. 2. Recommendations for sonography as a screening method.

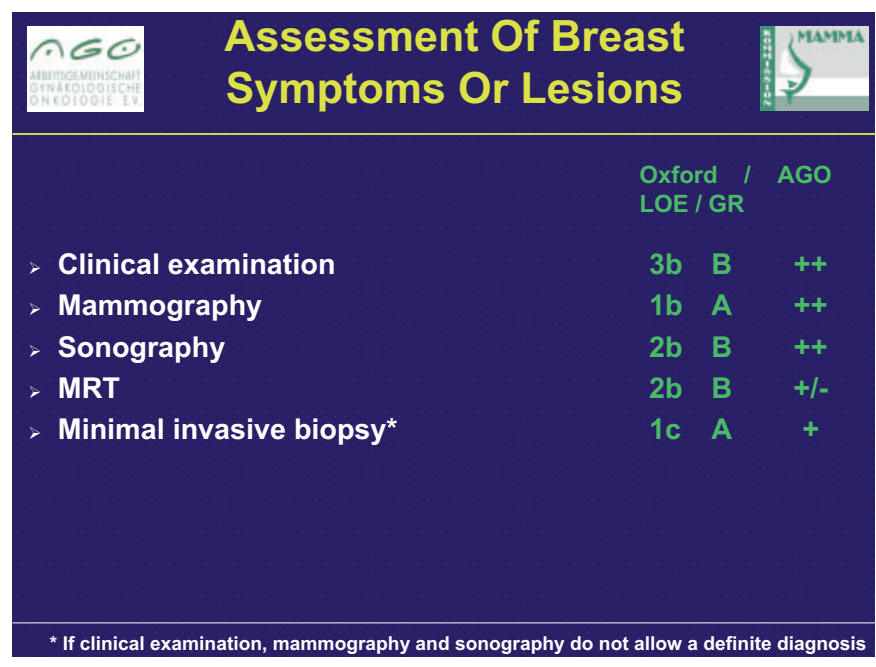

Fig. 3. Recommended methods for assessment of breast lesions.

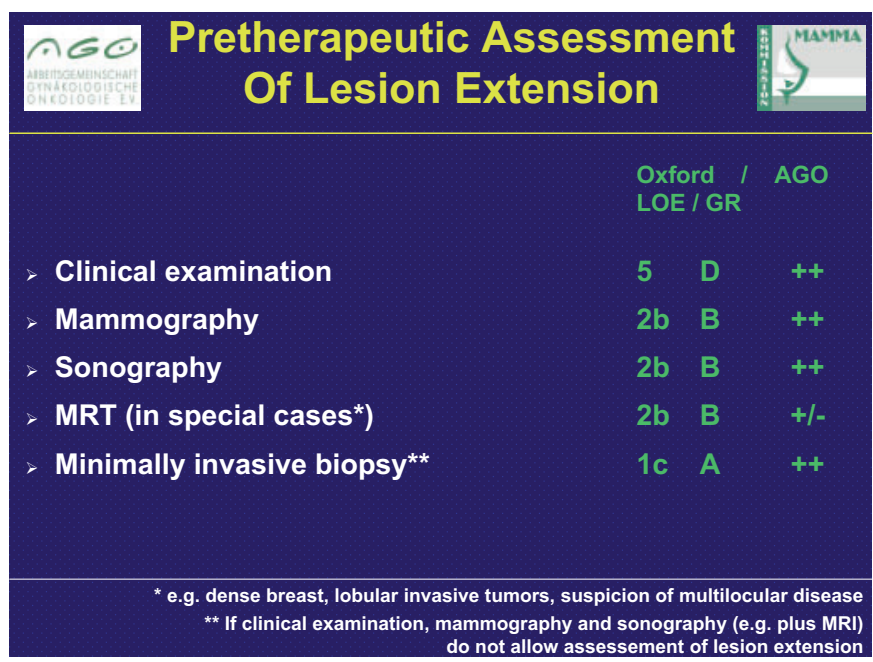

Fig. 4. Recommendations for pretherapeutic assessment of breast lesions.

tant reduction of specificity has to be expected (fig. 2). The role of breast ultrasound to further characterize a mammographic lesion and to determine its extent is well established and its use is strongly recommended. In contrast to the limitations of ultrasound and clinical examination on secondary prevention, breast imaging modalities, i.e. ultrasound and mammography together with clinical examination, are highly recommended to assess mammographic lesions or breast symptoms (fig. 3). Clinical breast examination composed of visual examination and systematic palpation is not sensitive enough to influence breast cancer mortality. This is also true for self examination as a stand-alone method and both examinations may even be harmful (detection of findings that result in an increase of benign biopsies).

Contrast-enhanced MRI plays a subordinate role in assessing breast symptoms or mammographic lesions apart from the detection of malignancy after augmentation, reconstruction, prothesis integrity, CUP syndrome and the differentiation between scarring and intramammary recurrence after breast conserving treatment. The high sensitivity is compromised by its lower specificity (fig. 3, 4). High-risk women, however, should benefit from MRI, but only under study conditions to further evaluate its effectiveness.

The highest sensitivity and accuracy in assessing breast lesions, both palpable and impalpable, is achievable with the use of percutaneous interventional procedures, i.e. core biopsy and vacuum-assisted biopsy with imaging guidance. Therefore, minimally invasive biopsy is strongly recommended for pretreatment histologic confirmation of malignancy (fig. 4).

\section{Reference}

1 Vainio H, Bianchini F (eds): IARC Handbooks of Cancer Prevention, vol 7. Breast Cancer Screening. Oxford, Oxford University Press, 2002. 